\title{
VPLIV PODNEBNIH SPREMEMB NA DINAMIKO GLIVNEGA RAZKROJA LESA V SLOVENIJI
}

\section{INFLUENCE OF CLIMATE CHANGE ON THE DYNAMICS OF THE FUNGAL DECAY OF WOOD IN SLOVENIA}

\author{
Miha HUMAR ${ }^{1}$, Boštjan LESAR², Davor KRŽIŠNIK ${ }^{3}$ \\ (1) Univerza v Ljubljani, Biotehniška fakulteta, Oddelek za lesarstvo, miha.humar@bf.uni-lj.si \\ (2) Univerza v Ljubljani, Biotehniška fakulteta, Oddelek za lesarstvo, bostjan.lesar@bf.uni-lj.si \\ (3) Univerza v Ljubljani, Biotehniška fakulteta, Oddelek za lesarstvo, davor.krzisnik@bf.uni-lj.si
}

\begin{abstract}
IZVLEČEK
Intenziteta glivnega razkroja je v največji meri odvisna od vrste lesa, temperature in padavinskih dogodkov. Če želimo oceniti življenjsko dobo in intervale vzdrževanja lesenih objektov, moramo oceniti, kako se bo v določenem okolju les obnašal. $V$ ta namen so nam na voljo raznoliki modeli. V praksi se največ uporablja pristop, ki ga je razvil Theodore Scheffer. Scheffer je predlagal klimatski indeks (Schefferjev klimatski indeks - SCI), ki temelji na številu padavinskih dni in povprečni mesečni temperaturi. Na podlagi teh klimatskih podatkov smo izračunali Schefferjev klimatski indeks za izbrane lokacije v Sloveniji. Rezultati analize klimatskih razmer kažejo, da je Schefferjev klimatski indeks v večini analiziranih krajev v Sloveniji višji, kot je bil pred desetletji. Intenziteta razkroja se je povečala v vseh analiziranih krajih z izjemo Portoroža. Največje zvišanje Schefferjevega klimatskega indeksa smo zaznali v Ratečah.
\end{abstract}

Ključne besede: les, Schefferjev klimatski indeks, razkroj, podnebne spremembe, temperatura, padavinski dogodki

\begin{abstract}
The intensity of fungal decay depends mainly on wood species, temperature and precipitation events. To estimate the planned service life of wood and to determine the maintenance intervals of wooden buildings, it is necessary to assess how wood behaves in a given environment. There are a variety of models that have been developed to assess the loading of wood. The approach most commonly used in practice is that developed by Theodore Scheffer. Scheffer proposed a climate index (Scheffer climate index) based on the number of rainy days and monthly average temperatures. Based on these data, Scheffer climate index for chosen locations in Slovenia was calculated. The results of the analysis of climatic conditions show that the Scheffer climate index is higher than it was decades ago at most of the analysed sites in Slovenia. The intensity of decomposition increased at all analysed locations, with the exception of Portorož. The largest increase in the Scheffer climate index was observed in Rateče.
\end{abstract}

Keywords: wood, Scheffer climate index, decay, climate change, temperature, rainfall events

GDK 844.2+111.83(497.4)(045)=163.6

DOI 10.20315/ASetL.125.5
Prispelo / Received: 6. 4. 2021

Sprejeto / Accepted: 14. 6. 2021

\section{UVOD}

1 INTRODUCTION

Les na prostem je izpostavljen delovanju raznolikega spektra biotskih in abiotskih dejavnikov (Humar in sod., 2020a). V naravi so ti procesi zaželeni, kadar les uporabljamo v gospodarske namene, pa želimo te procese čim bolj upočasniti, kajti povsem zaustaviti se jih ne da. V našem klimatskem okolju les najbolj ogrožajo glive (Schmidt, 2006; Humar in sod., 2019). Intenziteta glivnega razkroja na prostem je v največji meri odvisna od vrste lesa ter njene odpornosti proti škodljivcem, vlažnosti lesa in temperaturam. Minimalna vlažnost lesa, primerna za razkroj, je odvisna od vrste glive in vrste lesa. Praviloma se spodnja meja vlažnosti lesa, potrebna za razkroj, giblje v območju nasičenja celičnih sten med $25 \%$ in $30 \%$ (Schmidt, 2006). V zadnjem obdobju so številni avtorji dokazali, da lahko glive razkrajajo tudi les, ki ima vlažnost nižjo od območja nasičenja celičnih sten, vendar mora biti v bližini vir vode (Stienen in sod., 2014; Meyer in Brischke, 2015). Vlažnost lesa na prostem je odvisna od relativne zračne vlažnosti in $v$ še večji meri od padavinskih dogodkov (Humar in sod., 2020b). Najugodnejša temperatura za razvoj gliv je med $20{ }^{\circ} \mathrm{C}$ in $30{ }^{\circ} \mathrm{C}$ (Teodorescu in sod., 2017), vendar glive razkrojevalke lahko razkrajajo les v širšem območju, med $3{ }^{\circ} \mathrm{C}$ in $40^{\circ} \mathrm{C}$. V primeru, da je 
temperatura prenizka, voda zmrzne, s čimer je onemogočena rast (predvsem) gliv, pri višjih temperaturah pa že prihaja do denaturacije proteinov. Temperaturo in vlažnost lesa lahko skupaj opišemo kot klimo v materialu (ang. material climate) (Brischke in sod., 2008; Isaksson in Thelandersson, 2013).

Klima $\mathrm{v}$ materialu je $\mathrm{v}$ največji meri odvisna od temperature in padavinskih dogodkov. Če je klima $\mathrm{v}$ materialu v optimalnem območju za razvoj in rast gliv, razkroj poteka hitreje. Že dolgo je znano, da razkroj lesa v različnih klimatskih okoljih poteka različno hitro. Les v Sloveniji propade veliko hitreje kot na primer $\mathrm{v}$ deželah Skandinavije. Na primer, smrekovina v tretjem razredu uporabe (na prostem, dvignjeno od tal) v Ljubljani propade po 4 do 5 letih, v Oslu po 10 do 12 letih (Brischke in sod., 2013). Podnebni parametri so zato pomembne vhodne spremenljivke za modeliranje glivnega razkroja lesa, modeliranje življenjske dobe in kartiranje ogroženosti lesa. Pionirsko delo na področju kartiranja ogroženosti lesa zaradi glivnega razkroja je v zgodnjih sedemdesetih letih opravil Theodore Scheffer (Scheffer, 1971). Scheffer je predlagal klimatski indeks (SCI) za povezavo podnebnih podatkov s potencialnim glivnim razkrojem na določenem območju. Potencial nevarnosti za različne podnebne razmere $\mathrm{v}$ ZDA je bil ocenjen z empirično določeno intenzivnostjo razkroja lesa na terenskih testih. Višji kot je SCI, večja

Preglednica 1: Seznam klimatoloških postaj, za katere smo pridobili klimatološke podatke za izračun Schefferjevega klimatskega indeksa je nevarnost za razkroj lesa. Vrednosti SCI se v kontinentalnem delu ZDA gibajo med 0,0 (Yuma, Arizona) in 137,5 (West Palm Beach, Florida) (Scheffer, 1971). Kasneje so ta pristop uporabile še druge države, kot so Kanada, Koreja, Kitajska, Japonska, Avstralija, Norveška, Španija in Grčija (Brischke in Selter, 2020).

Analiza ogroženosti lesa v odvisnosti od klimatskih razmer v Sloveniji še ni bila opravljena. Vrednotenje ogroženosti lesa ima danes še večji pomen kot v preteklosti predvsem zaradi naraščajočega pomena lesene gradnje (Kitek Kuzman in sod., 2018), omejitve rabe biocidov v EU (528/2012) in naraščajočega pomena rabe domačih lesnih vrst (Humar in sod., 2006), uvedbe BIM-projektiranja (informacijskega modeliranja $\mathrm{v}$ gradbeništvu) (Humar in sod., 2020a) in klimatskih sprememb (Kutnar in Kobler, 2011; Hanewinkel in sod., 2013). Podnebne spremembe se dogajajo, meritve kažejo na trend dvigovanja temperature zraka. Zadnjih deset let sodi med najtoplejša leta v času opazovanja vremena v Sloveniji. Poleg tega smo vse pogosteje priča tudi vedno intenzivnejšim ekstremnim vremenskim dogodkom, od žleda do viharjev, toče ... (Bertalanič in Dolinar, 2018). Vpliv klimatskih sprememb na rabo lesa bo razviden na več nivojih. Klimatske spremembe bodo vplivale na kakovost in razpoložljivost lesa. Pojavile se bodo nove lesne vrste, ki jih v svojem okolju ne poznamo (Hanewinkel in sod., 2013; Čater, 2014). Dinamika

Table 1: List of climatological stations for which we obtained climatological data for the calculation of the Scheffer climate index

\begin{tabular}{|c|c|c|}
\hline $\begin{array}{l}\text { Klimatološka postaja } \\
\text { Climatological station }\end{array}$ & $\begin{array}{l}\text { Obdobje meritev } \\
\text { Period of monitoring }\end{array}$ & $\begin{array}{c}\text { Nadmorska višina [m] } \\
\text { Altitude }[\mathrm{m}]\end{array}$ \\
\hline \multirow{2}{*}{ Bilje } & Nova Gorica (1970-1990) & 93 \\
\hline & Bilje (1991-2020) & 55 \\
\hline \multirow{2}{*}{ Bohinjska Češnjica } & Stara Fužina (1970-2001) & 548 \\
\hline & Bohinjska Češnjica (2002-2020) & 507 \\
\hline Ljubljana & Ljubljana (1948-2020) & 299 \\
\hline \multirow{3}{*}{ Maribor } & Maribor Tezno (1949-1962) & 262 \\
\hline & Maribor Tabor (1963-2004) & 275 \\
\hline & Letališče Maribor (2005-2020) & 267 \\
\hline \multirow{2}{*}{ Murska Sobota } & Murska Sobota (1953-1955) & 189 \\
\hline & Rakičan (1956-2020) & 186 \\
\hline \multirow{3}{*}{ Novo mesto } & Kandija (1952-1960) & 220 \\
\hline & Gotna vas (1961-1972) & 183 \\
\hline & Novo mesto (1973-2020) & 220 \\
\hline \multirow{3}{*}{ Portorož } & Koper (1954-1974) & 54 \\
\hline & Beli Križ (1975-1990) & 93 \\
\hline & Portorož (1991-2020) & 2 \\
\hline Rateče & Rateče (1951-2020) & 863 \\
\hline \multirow{2}{*}{ Tolmin } & Most na Soči (1949-1952) & 179 \\
\hline & Tolmin (1953-1990) & 201 \\
\hline
\end{tabular}


glivnega razkroja v Sloveniji se bo spremenila. Poleg tega se lahko pojavijo še novi škodljivci, kot na primer termiti, ki lahko na določenem geografskem območju naredijo veliko škodo (Pohleven in Humar, 2000).

Namen tega prispevka je izračunati Schefferjev klimatski indeks za izbrane slovenske kraje in prikazati, kako se je SCI spreminjal v zadnjih desetletjih. Podatke lahko uporabimo tudi za oceno ogroženosti obstoječega stavbnega fonda, predvsem kulturne dediščine, ki je nastala v povsem drugačnih klimatskih okoliščinah.

\section{METODE}

\section{METHODS}

Analiza je bila opravljena na izbranih lokacijah v Sloveniji, kjer se opravljajo dolgoletne meteorološke meritve v okviru mreže državnih klimatoloških postaj. Ker so se nekatere merilne postaje $\mathrm{z}$ leti nekoliko prestavljale, smo postaje na ključnih lokacijah smiselno združevali (preglednica 1).

Podatke o povprečnem številu padavinskih dni in povprečni mesečni temperaturi smo pridobili iz arhiva Agencije Republike Slovenije za okolje (ARSO, 2020). Schefferjev klimatski indeks (SCI) je bil izračunan v skladu z naslednjo enačbo (Scheffer, 1971):

$$
S C I=\sum_{\operatorname{Jan}}^{\operatorname{Dec}}\left[\frac{(T-2)(D-3)}{16,7}\right]
$$

$\mathrm{T}$ - povprečna mesečna temperatura $\left[{ }^{\circ} \mathrm{C}\right]$

D - število dni, ko dnevna količina padavin preseže $0,25 \mathrm{~mm}$

Podatki v arhivu ARSO podajajo mejo, za padavinski dan 0,1 mm padavin, Schefferjev klimatski indeks pa uporablja nekoliko višjo mejo $(0,25 \mathrm{~mm})$. Ker nam iz arhiva ARSO ni uspelo pridobiti podatkov o številu dni, ko padavine presežejo $0,25 \mathrm{~mm}$, temveč le za 0,1 mm smo Schefferjev klimatski indeks izračunali na podlagi obstoječih podatkov in število padavinskih dni korigirali z indeksom, tako da se ujema s SCI za referenčno obdobje v Ljubljani (1990-2010). Referenčna vrednost SCI za Ljubljano znaša 55,3 (Humar in sod., 2019; Ugovšek in sod., 2019). SCI smo izračunali za celotno obdobje meritev, kot drseče povprečje desetletnih meritev.

\section{REZULTATI IN RAZPRAVA}

\section{RESULTS AND DISCUSSION}

Pri analizi ogroženosti lesa smo se osredotočili na ključna dejavnika, ki vplivata na dinamiko razkroja lesa; temperaturo ter število padavinskih dni. Iz teh dveh kazalnikov smo izračunali Schefferjev klimat- ski indeks (SCI). Kot posledico globalnega segrevanja smo na večini opazovanih postajah zaznali povišanje temperatur (slika 1). Če med seboj primerjamo desetletji 1970-1980 in 2010-2020, vidimo, da se je temperatura najbolj izrazito povišala $v$ Ratečah, kjer se je povprečna temperatura $s 5,5^{\circ} \mathrm{C}$ dvignila na $7,6^{\circ} \mathrm{C}$. Ta razlika kaže, da je povprečna temperatura $v$ Ratečah znatno višja. Največji absolutni dvig povprečne temperature smo zabeležili v Ljubljani, kjer se je povprečna temperatura dvignila za $2,4^{\circ} \mathrm{C}, \mathrm{z} 9,7^{\circ} \mathrm{C}(70$. leta 20 . stoletja) na $12,1^{\circ} \mathrm{C}$ (20. leta 21 . stoletja), oziroma za $25 \%$. Po drugi strani smo najmanj izrazit dvig temperature v absolutnem in relativnem smislu zabeležili v Portorožu z izrazitim vplivom morja. V Portorožu se je povprečna temperatura v zadnjih 40 letih dvignila za $0,8^{\circ} \mathrm{C}$. Če med seboj primerjamo posamezne lokacije (slika 2), je razvidno, da je najvišja povprečna temperatura $v$ opazovanem obdobju v Portorožu $\left(13,7^{\circ} \mathrm{C}\right)$ in najnižja v Ratečah $\left(6,3^{\circ} \mathrm{C}\right)$. Za Slovenijo velja, da se temperatura dvigne za približno $0,36^{\circ} \mathrm{C}$ na desetletje (Bertalanič in Dolinar, 2018). Tako je pričakovati, da se bo trend naraščanja temperatur v prihodnje še nadaljeval.

Poleg temperature ima na dinamiko razkroja lesa velik vpliv tudi število padavinskih dni. Slovenija je zaradi lege v zmernih geografskih širinah in bližine morja na zahodni strani celine razmeroma dobro namočeno območje (Bertalanič in Dolinar, 2018). Enakomerno razporejene padavine imajo pozitiven vpliv na kmetijstvo in rastlinstvo, a po drugi strani izrazito negativno vplivajo na življenjsko dobo lesa na prostem. Bolj kot količina padavin ima na dinamiko razkroja lesa vpliv število padavinskih dni. Znano je, da v posameznem padavinskem dogodku lahko pade $100 \mathrm{~mm}$ ali več padavin. Ker je prodiranje vode v les počasno, ima bolj kot sama količina padavin na vlažnost lesa vpliv število padavinskih dni (Humar in Lesar, 2020). Glede padavinskih dni izrazito prednjačita Ljubljana in Bohinj (slika 1).

Število padavinskih dni se je na vseh opazovanih postajah zmanjšalo. V Portorožu je bilo zmanjšanje števila padavinskih dni najbolj opazno, ker je v zadnjih 40 letih upadlo za kar $14 \%$ (slika 1). Na drugih lokacijah je bilo zmanjšanje števila padavinskih dni manj izrazito, in znaša okoli $5 \%$, z izjemo Rateč, kjer je število padavinskih dni zadnja desetletja konstantno. Če med seboj primerjamo posamezne lokacije (slika 2), je razvidno, da je povprečno število padavinskih dni najvišje v Bohinju (158), sledita Ljubljana in Tolmin (156). Po pričakovanju je najmanj deževnih dni v Portorožu (115). Zaradi milih temperatur in velikega števila deževnih dni sodi Ljubljana med mesta $\mathrm{z}$ najugodnejšim podnebjem za razvoj rjave trohnobe (Brischke in sod., 

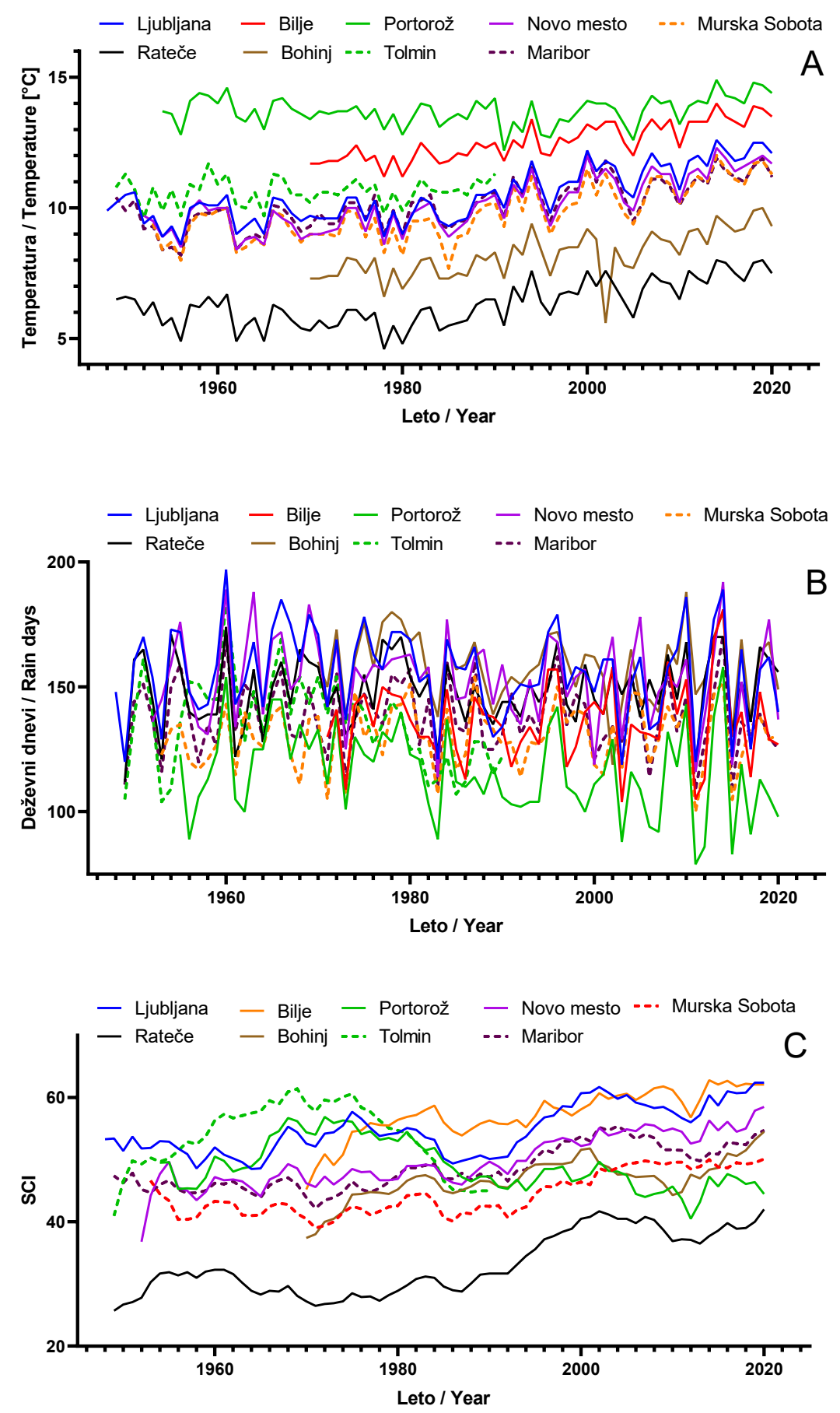

Slika 1: Gibanje povprečne letne temperature (A), padavinskih dni (B) in Schefferjevega klimatskega indeksa (SCI) (C) v izbranih slovenskih krajih

2008, 2013). K temu v največji meri pripomorejo padavinski dogodki, ki so enakomerno razporejeni prek leta.

Schefferjev klimatski indeks na preprost način povzema tako vpliv temperature kot padavinskih dni. Iz primerjave SCI med različnimi kraji v Sloveniji je razvidno, da imata najvišji SCI Bilje $(58,6)$ in Ljubljana $(55,5)$. Najnižja SCI smo izračunali za Rateče $(34,0)$ in
Fig. 1: Course of the average annual temperature (A), number of rainy days (B) and Scheffer climate index (SCI)(C) in selected Slovenian locations

Mursko Soboto $(45,0)$. Te vrednosti so povprečja SCI za celotno obdobje opravljanja meritev. V zadnjih desetletjih je opaziti, da se je SCI v večini Slovenije izrazito povečal. Najbolj izrazito povečanje SCI je v Ratečah, kjer je v 40 letih narasel z 28,9 na 42,0. To je v veliki meri posledica toplejših zim. Pred štirideset in več leti so bile temperature pozimi dovolj nizke, da razkroj lesa skozi dobršen del leta ni potekal. V zadnjih letih 

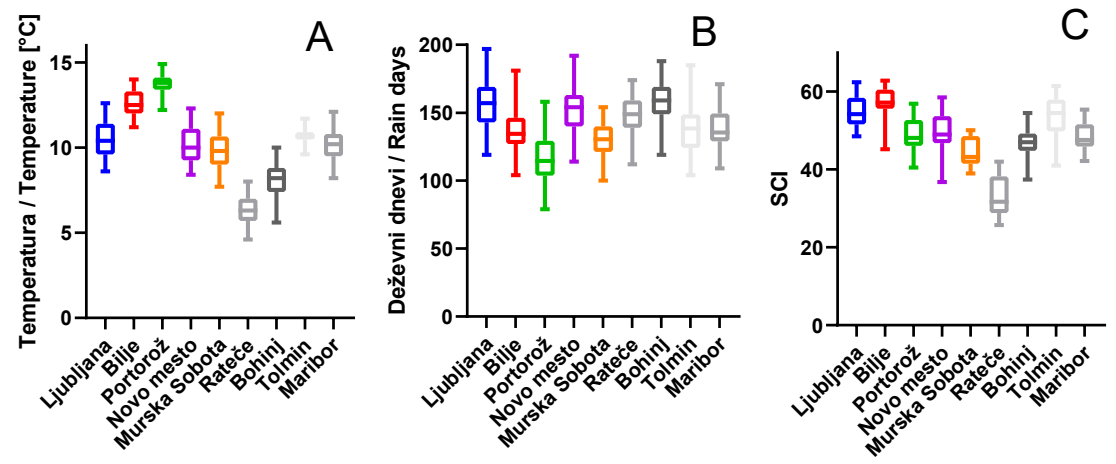

Slika 2: Povprečna letna temperatura (A), povprečno število padavinskih dni (B) in povprečni Schefferjev klimatski indeks (SCI) (C) v izbranih slovenskih krajih za obdobja, razvidna v preglednici 1

zaradi višjih temperatur razkroj pogosto poteka tudi pozimi. Opazen dvig SCI smo opazili tudi v Novem mestu (25\%) in Bohinju (21\%). Edino v Portorožu se je SCI zmanjšal s 53 na 45, kar pomeni, da je ogroženost lesa zaradi delovanja gliv razkrojevalk danes nižja kot pred desetletji. K temu največ prispevata drugačen padavinski režim in najmanjši dvig povprečne temperature. Po drugi strani se v Istri pojavljajo novi škodljivci, predvsem termiti, katerih življenjski prostor se zaradi segrevanja ozračja stalno širi v nova območja (Ewart in sod., 2017). Ti pomenijo grožnjo, ki je s SCI ne moremo ovrednotiti. SCI indeks je namenjen določanju izpostavljenosti lesa glivnemu razkroju.

Glede na naraščajoči trend lesene gradnje je nujno upoštevati naraščajočo ogroženost lesa zaradi delovanja lesnih gliv. Ogroženost lesa se povečuje tudi v Ljubljani (slika 3). To pomeni, da moramo skrbneje upoštevati pravila lesene gradnje in uporabiti ustrezno zaščito povsod, kjer je to potrebno. Pri tem se ne smemo več zanašati le na izkušnje, temveč se moramo držati standardov in priporočil stroke. Zaradi podnebnih sprememb se spreminjajo tako lastnosti lesa kot tudi
Fig. 2: Average yearly temperatures (A), average number of rainy days (B) and average Scheffer climate index (SCI) (C) in selected Slovenian locations for the periods listed in Table 1

dinamika razkroja. To v uporabo vnaša veliko negotovost, ki je ne moremo razumeti le na podlagi preteklih izkušenj. Nujno je, da neprekinjeno opravljamo meritve mikroklimatskih razmer v lesu (Kržišnik in sod., 2018) in s terenskimi testi spremljamo dinamiko razkroja lesa v spreminjajočem se okolju (Humar in sod., 2019). Le na podlagi teh opazovanj bomo lahko dovolj zgodaj prilagodili leseno gradnjo novim razmeram.

Navsezadnje je treba upoštevati, da je dobršen del kulturne dediščine v Sloveniji delno ali v celoti izdelan iz lesa (RKD, 2019). Ta je še posebej ogrožena, saj je nastala v povsem drugih klimatskih razmerah. Kot je razvidno iz predstavljenih rezultatov, je še posebej izpostavljena dediščina $\mathrm{v}$ Alpskih dolinah. Iz Trente na primer že poročajo, da lesena kritina danes ni tako trajna, kot nekoč (Humar in Lesar, 2020), saj les hitreje propada kot v preteklosti. Zato je nujno, da se zavedamo, da moramo za ohranjanje kulturne dediščine uporabiti nova znanstvena spoznanja o lastnostih lesa, postopkih zaščite in spremenjenem podnebju, če jo želimo ohraniti zanamcem.

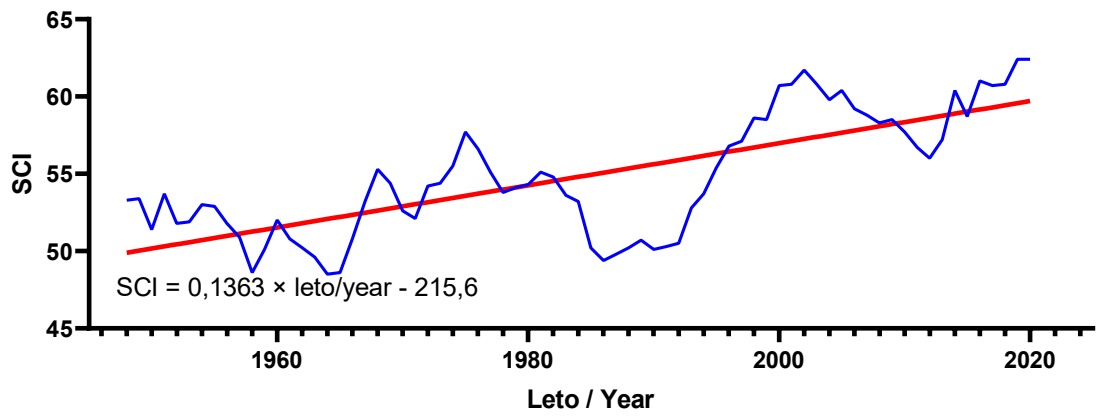

Slika 3: Sprememba Schefferjevega klimatskega indeksa

Fig. 3: Changes of Scheffer climate index (SCI) in Ljubljana (SCI) v Ljubljani 


\section{ZAKLJUČKI}

\section{CONCLUSIONS}

Les na prostem je izpostavljen delovanju širokega spektra škodljivcev. V naših klimatskih razmerah so še posebej nevarne glive. Intenziteta glivnega razkroja je v največji meri odvisna od vrste lesa, temperature in padavinskih dogodkov. Na podlagi teh podatkov smo izračunali Schefferjev klimatski indeks. Modeli za vrednotenje ogroženosti kažejo, da razkroj lesa zaradi podnebnih sprememb poteka vedno hitreje. Intenziteta razkroja se je povečala $\mathrm{v}$ vseh analiziranih krajih z izjemo Portoroža. Največje zvišanje Schefferjevega klimatskega indeksa smo zaznali v Ratečah.

\section{ZAHVALA}

\section{ACKNOWLEDGMENTS}

Prispevek je rezultat več med seboj povezanih projektov, ki jih je sofinancirala Agencija za raziskovalno dejavnost RS: V4-2017 - Izboljšanje konkurenčnosti slovenske gozdno-lesne verige $\mathrm{v}$ kontekstu podnebnih sprememb in prehoda v nizkoogljično družbo; P4-0015 - Programska skupina les in lignocelulozni kompoziti. Del raziskav je potekal tudi v okviru projekta Durasoft znotraj programa Interreg Slovenija-Italija.

\section{POVZETEK}

\section{SUMMARY}

Wood is an important building material that has been used for thousands of years. After a few decades of decline, the importance of timber construction in Slovenia is increasing again. New designs and construction practices, and especially the introduction of building information modelling, have increased the need for more data on the service life of wood and other derived materials. In our climate zone, wood is vulnerable mainly to fungal decay. To estimate the expected service life of wood and determine the maintenance intervals of wooden buildings, it is necessary to estimate how the wood will behave in a given environment. There are a variety of models that have been developed to evaluate the exposure of wood. The approach most commonly used in practice is that developed by Theodore Scheffer. Scheffer proposed a climate index (Scheffer's climate index). Although this approach has been known for decades, it has not yet been introduced in Slovenia. This manuscript represents the first use of this approach in Slovenia to evaluate the intensity of climate in relation to wood rot.

The intensity of fungal decay depends largely on wood species, temperature and precipitation events. Based on these data, we calculated Scheffer's climate index. The climatic data were obtained from the Slo- venian Environment Agency. The analysis of climatic conditions shows that Scheffer's climate index is higher than decades ago at most of the analysed sites in Slovenia. The severity of the climate has increased at all analysed sites, except for Portorož, due to its proximity to the sea. The most significant increase in the Scheffer climate index was observed in Rateče, where it increased from 28.9 to 42.0 , meaning that decay will proceed faster than it did in the past. Higher climate index values indicate that Slovenia's wooden cultural heritage is at risk, with significant damage and loss of valuable objects possible given that they were designed for different climatic conditions.

\section{LITERATURA}

\section{REFERENCES}

ARSO. 2020. Agencija Republike Slovenije za okolje. http://meteo. arso.gov.si/met/sl/archive/ (17.1.2021).

Bertalanič R., Dolinar M. 2018. Ocena podnebnih sprememb v Sloveniji do konca 21. stoletja: sintezno poročilo. Ljubljana, Ministrstvo za okolje in prostor, Agencija Republike Slovenije za okolje.

Brischke C., Meyer L., Alfredsen G., Humar M., Francis L., Flæte P.O., Larsson-Brelid P. 2013. Prirodna trajnost drva izloženoga iznad zemlje - pregled istraživanja. Drvna Industrija, 64, 2: 113-129. https://doi.org/10.5552/drind.2013.1221

Brischke C., Rapp A.O., Bayerbach R., Morsing N., Fynholm P., Welzbacher C.R. 2008. Monitoring the "material climate" of wood to predict the potential for decay: results from in situ measurements on buildings. Building and Environment, 43, 10: 15751582. https://doi.org/10.1016/j.buildenv.2007.10.001

Brischke C., Selter V. 2020. Mapping the decay hazard of wooden structures in topographically divergent regions. Forests, 11, 5: 1-16. https://doi.org/10.3390/F11050510

Čater M. 2014. Mortality and crown conditions on Quercus robur L. permanent plots - a 20-year overview. Acta Silvae et Ligni, 105: 17-25. https://doi.org/10.20315/asetl.105.2

EwartD., Nunes L., Troya T.de, Kutnik M. 2017. Termites and a changing climate. V: Climate change impacts on urban pests. Dhang P. (ur.). CABI: 80-94. https://doi.org/10.1079/9781780645377.0080

Hanewinkel M., Cullmann D.A., Schelhaas M.J., Nabuurs G.J., Zimmermann N.E. 2013. Climate change may cause severe loss in the economic value of European forest land. Nature Climate Change, 3, 3: 203-207. https://doi.org/10.1038/nclimate1687

Humar M., Kržišnik D., Lesar B., Brischke C. 2019. The performance of wood decking after five years of exposure: verification of the combined effect of wetting ability and durability. Forests, 10, 10: 17. https://doi.org/10.3390/f10100903

Humar M., Lesar B. 2020. Spremljanje vlažnosti lesene strehe golobarske žičnice - preliminarni rezultati. Acta Silvae et Ligni, 122: 19-28. https://doi.org/10.20315/asetl.122.2

Humar M., Lesar B., Kržišnik D. 2020a. Technical and aesthetic service life of wood. Acta Silvae et Ligni, 121: 33-48. https://doi. org/10.20315/asetl.121.3

Humar M., Lesar B., Kržišnik D. 2020b. Moisture performance of façade elements made of thermally modified Norway spruce wood. Forests, 11, 3: 1-13. https://doi.org/doi.org/10.3390/ f11030348

Humar M., Peek R.D., Jermer J. 2006. Regulations in the European Union with emphasis on Germany, Sweden and Slovenia. V: Townsend V.T.G., Solo-Gabriele H. (ur.). Environmental impacts of treated wood. Boca Raton, CRC Press: 520 str. 
Isaksson T., Thelandersson S. 2013. Experimental investigation on the effect of detail design on wood moisture content in outdoor above ground applications. Building and Environment, 59: 239249. https://doi.org/10.1016/j.buildenv.2012.08.023

Kitek Kuzman M., Klarić S., Pirc Barčić A., Vlosky R.P., Janakieska M.M., Grošelj P. 2018. Architect perceptions of engineered wood products: an exploratory study of selected countries in Central and Southeast Europe. Construction and Building Materials, 179: 360-370. https://doi.org/10.1016/j.conbuildmat.2018.05.164

Kržišnik D., Lesar B., Thaler N., Humar M. 2018. Micro and material climate monitoring in wooden buildings in sub-Alpine environments. Construction and Building Materials, 166: 188-195. https://doi.org/10.1016/j.conbuildmat.2018.01.118

Kutnar L., Kobler A. 2011. Prediction of forest vegetation shift due to different climate-change scenarios in Slovenia. Šumarski list, 135, 3-4: 113-126.

Meyer L., Brischke C. 2015. Fungal decay at different moisture levels of selected European-grown wood species. International Biodeterioration and Biodegradation, 103: 23-29. https://doi. org/10.1016/j.ibiod.2015.04.009

Pohleven F., Humar M. 2000. Termiti - nevarni škodljivci tudi v Sloveniji? Les, 52, 11: 369-373.
RKD. 2019. Register kulturne dediščine. https://gisportal.gov.si/ portal/apps/webappviewer/index.html?id=df5b0c8a300145fd a417eda6b0c2b52b (21. 3. 2021).

Scheffer C.T. 1971. Climate index for estimating potential for decay in wood structures above ground. Forest Products Journal, 21, 10: $25-31$.

Schmidt 0. 2006. Wood and tree fungi: biology, damage, protection, and use. Berlin Heidelberg, Springer. https://doi. org/10.1007/3-540-32139-X

Stienen T., Schmidt O., Huckfeldt T. 2014. Wood decay by indoor basidiomycetes at different moisture and temperature. Holzforschung, 68, 1: 9-15. https://doi.org/10.1515/hf-2013-0065

Teodorescu I., Țăpuşi D., Erbaşu R., Bastidas-Arteaga E., Aoues Y. 2017. Influence of the climatic changes on wood structures behaviour. Energy Procedia, 112: 450-459. https://doi. org/10.1016/j.egypro.2017.03.1112

Ugovšek A., Šubic B., Starman J., Rep G., Humar M., Lesar B., ... Lozano J.I. 2019. Short-term performance of wooden windows and facade elements made of thermally modified and non-modified Norway spruce in different natural environments. Wood Material Science and Engineering, 14, 1: 42-47. https://doi.org/10.10 80/17480272.2018.1494627 